\title{
How does the Type of Task Influence the Performance and Social Regulation of Collaborative Learning?
}

\author{
Santiago Roger Acuña ${ }^{1}$, Gabriela López-Aymes ${ }^{2}, \&$ Silvia T. Acuña-Castillo ${ }^{3}$ \\ ${ }^{1}$ Facultad de Ciencias de la Comunicación, Universidad Autónoma de San Luis Potosí, SLP, México \\ ${ }^{2}$ Facultad de Comunicación Humana, Universidad Autónoma del Estado de Morelos, México \\ ${ }^{3}$ Escuela Politécnica Superior, Universidad Autónoma de Madrid, España \\ Correspondence: Santiago Roger Acuña, Facultad de Ciencias de la Comunicación, Universidad Autónoma de San \\ Luis Potosí, Avda. Karakorum Nª 1245, Lomas 4 Sección, CP 78215, San Luis Potosí, S.L.P., México.
}

Received: January 24, 2018

Accepted: February 20, 2018

Online Published: March 10, 2018

doi:10.5430/ijhe.v7n2p28

URL: https://doi.org/10.5430/ijhe.v7n2p28

\begin{abstract}
In this paper we analyze the effects of the type of collaborative task (elaboration of concept map vs elaboration of expository summary) on the performance and on the level of collaboration achieved by Mexican university students in the multimedia learning of a social sciences content (Communication Psychology). Likewise, the processes of social regulation that are put into play in these collaborative tasks are described. Forty-five students (17 women and 28 men) grouped in 15 triads participated in the study. Each triad was assigned to one of the two collaborative conditions: elaboration of concept map ( 8 groups) and elaboration of an expository summary (7 groups). It was monitored that there were no significant previous differences between two conditions regarding: reading comprehension, reading comprehension regulation strategies and domain-specific prior knowledge. To evaluate the performance in learning, the quality of the proposals made in concept maps and summaries were taken adapting the procedure proposed by Haugwitz, Nesbit and Sandmann (2010), and also the results obtained by the students in a multiple-choice questionnaire about the knowledge area. Likewise, the level of collaboration perceived by each member of the teams was examined using a Collaboration questionnaire developed by Chan and Chan (2011). The identification and characterization of the processes of social regulation was carried out through a qualitative analysis of the exchanges registered during the collaborative activity, considering the type (co-regulation and shared regulation) and the regulation orientation (directed to the task or to the management of collaboration). The quantitative results analysis showed the existence of significant effects working with collaborative concept maps in the knowledge acquired during the collaborative task and in some of the indicators of perceived collaboration. Although no significant statistical differences were found, in the teams that elaborated expository summaries, a predominance of episodes of regulation directed towards the cognitive activity of the collaborative task was observed, being scarce, in both conditions, the episodes of social regulation directed towards collaboration within the triads.
\end{abstract}

Keywords: collaborative learning, concept maps, social regulation, learning tasks

\section{Introduction}

Research on collaborative learning has emphasized the influence that different digital technological tools have, either to promote greater performance in learning and to enrich the dynamics of exchanges between apprentices during collaborative activity (for a review, Dillenbourg, Järvelä, \& Fischer, 2009).

According to Lethinen, Hakkarainen, Lipponen, Rahikainen, \& Muukkonen (1999), it is possible to distinguish two ways of using technologies in collaborative learning. On the one hand, these tools could function as a channel through which the communication between the apprentices is more viable, for example, an online learning platform that includes a discussion forum. Reference would be made, in this sense, to collaboration "through" technology. However, on the other hand, digital instruments, such as multimedia, hypermedia and virtual simulators, can also become the focal point around which interactions between students will be generated. In this case, conversations and discussions among the apprentices, which would constitute significant moments for learning, would generate "around" the technology. Then, in these dialogues, students can express their own ideas, contrast their points of view about the content to learn and regulate their own processes of joint understanding (Manlove, Lazonder, \& de Jong, 2009). 
Also, given that the mere presence of technologies does not automatically generate collaborative learning, the convenience of organizing collaboration in instructional that are enriching, challenging and authentic for students has been pointed out (Jeong \& Hmelo-Silver, 2016). In this sense, Chi and Wylie (2014) have highlighted the importance of proposing to learner's tasks that allow them to be "constructively interactive". That is, tasks that promote not only greatest interaction, but also encourage interactions related to the joint construction of knowledge, such as proposing ideas, asking questions, providing explanations, refuting points of view and generating arguments and justifications (Chi, 2009).

Chi and collaborators (Chi, 2009; Chi \& Menekse, 2015; Chi \& Wylie, 2014) have proposed an explanatory framework to analyze and compare different learning task modalities: the ICAP framework. Specifically, they have been concerned with examining the type of actions and processes that these tasks allow students to elicit and also their impact on learning levels. They have proposed a growing sequence of different types of learning activities, ranging from very basic tasks with less potentials for learning, such as passive activities (for example, listening to an exhibition or watching a video), followed by active tasks (for example, taking notes or underlining main ideas), continuing with constructive tasks (for example, generating self-explanations, making inferences, making comparisons), until reaching a higher level, corresponding to interactive tasks, in which students work jointly in the generation of a new product. Chi and Wylie (2014) have found favorable evidence to the hypothesis that the greater the involvement in learning activities -considering the increasing sequence: passive, active, constructive and interactive-, students are more encouraged to put processes and mechanisms of greater complexity into play, which in turn has an impact on greater learning. Therefore, higher levels of learning appear when apprentices are involved, for example, in the generation of inferences and in discussion and negotiation of different points of view, among other actions, that allow them to go beyond the learning material, to co-create knowledge (Chi \& Menekse, 2015; Chi \& Wylie, 2014).

In addition, it is required that these tasks favor the development and the explicitation of cognitive, metacognitive and motivational processes, related to social regulation during the collaborative activity (Jeong \& Hmelo-Silver, 2016; O’Donnell \& Hmelo-Silver, 2013; Schoor, Narciss, \& Körndle, 2015). Social regulation refers to the modes of regulation that appear at the group level, either when an apprentice regulates himself with respect to a group goal, or when the students help each other to regulate their actions, or when the group as a whole is regulated in a shared way (Schoor et al., 2015). In collaborative learning, social regulation is a key process not only for the generation of a collaborative product but also for managing exchanges during the development of this task (Hadwin, Järvelä, \& Miller, 2011; Järvelä \& Hadwin, 2013). However, previous research has shown that, in general, students have difficulties to regulate collaborative interactions (Acuña, López-Aymes, \& Gabino-Campos, 2012; Rogat \& Linnenbrink-Garcia, 2011; Summers \& Volet, 2010).

In spite of it could be considered that the "synergistic" combination in the collaborative activity of technological supports and constructively interactive tasks, would allow configuring a "double scaffolding" instructional scenario. Through these scaffolds would favor greater social regulation, necessary for the generation of a common awareness about the goals, execution and monitoring of coordinated and interdependent actions and the joint and negotiated construction of knowledge that demands the development of a collaborative product (Järvenoja, Järvelä, \& Malmberg, 2015; Schoor \& Bannert, 2012; Volet, Vauras, \& Salonen, 2009).

In this sense, a task of concept maps like collaborative construction for the acquisition of knowledge using hypermedia materials - when gathering constructive and interactive characteristics - would have a range of potentialities to promote greater learning and also to elicit different processes of high complexity, among them corresponding to social regulation. For instance, van Boxtel, van der Linden, Roelofs, and Erkens (2002) have pointed out that the use of collaborative concept maps would induce students to engage in two fundamental types of actions for learning: a) elaborative actions; and, b) actions of negotiation of meanings.

First, collaborative concept maps offer a wide range of possibilities to generate interactions that propitiate the elaboration of knowledge. For instance, the amount of shared information would increase by presenting it visually, in a concrete and synthetic way. The collaborative construction of the concept map induces students to identify the concepts presented in the text, to exchange the meanings they attribute to these concepts, and to explain the existing relationships between these ideas. Second, following van Boxtel et al. (2002), the collaborative concept mapping can create suitable conditions for the emergence of knowledge negotiation actions, in which students are not only forced to reflect and elaborate their own knowledge, but also need to consider, integrate and elaborate the knowledge of their teammates. 
Indeed, concept mapping have been used as an instructional strategy to promote understanding and knowledge acquisition in collaborative learning situations (Chang, Sung, \& Chen, 2001; Hilbert \& Renkl, 2009). Despite the fact that research on collaborative concept maps has proven its positive effects with respect to the individual construction of concept maps and also against other collaborative learning tasks (for a review, Basque \& Lavoie, 2006; Gao, Shen, Losh, \& Turner, 2007, Nesbit \& Adesope, 2006), some studies have found discrepant evidence in comparison with other collaborative tasks of similar characteristics, such as the joint elaboration of summaries and posters (Fechner \& Sumfleth, 2008; Haugwitz et al., 2010; van Boxtel, van der Linden, \& Kanselaar, 2000). These research, above all, have been directed to analyze their influence on learning and describe the quality of the exchanges in these collaborative activities, still being incipient the study of the processes of social regulation and the levels of collaboration that reach in this kind of learning.

In this work we study collaborative learning around a digital multimedia technology (multimedia text on a subject of Communication Psychology). Specifically, the influence of the type of collaborative task (concept map and expository summary) on the processes of social regulation of learning that Mexican university students carry out when they learn collaboratively in triads is analyzed, as well as their effects on the learning performance, and on the level of collaboration that students perceive in their different groups. First, the theoretical and empirical background of the study is presented. Second, the followed methodology is described and the results obtain are reported. Finally, some implications for the instructional use of collaborative concept mapping are pointed out.

\subsection{Multimedia Learning with Collaborative Concept Maps and Social Regulation Processes}

Learning collaboratively with digital tools, such as multimedia and hypermedia texts, requires that the trainers deploy a series of highly complex cognitive, metacognitive and motivational mechanisms to process textual and pictorial information - in an integrated and constructive way - that is presented in a non-linear sequence (Jonassen, Lee, Young, \& Laffey, 2005). To which is added the need to deploy skills, sophisticated as well, for planning, management and joint supervision in the group, namely, put into the social regulation processes to properly structure collaboration (Molenaar, Sleegers, \& van Boxtel, 2014; Schoor et al., 2015; Volet et al., 2009).

In addition to the self-regulation a student carries out on himself when he learns with a group on a joint goal, social regulation encompasses: a) co-regulation, that is, the regulation that is established in an asymmetric situation in which one of the members of a group (for having greater knowledge and regulation skills) guide and support the self-regulatory competence of the other members in the group; and, b) socially shared regulation, which refers to the most advanced and complex regulatory processes that emerge when a group is jointly regulated as a collective, in a symmetrical situation, in which it can jointly build a common awareness about the goals, the monitoring and supervision strategies and the management of the exchanges that suppose a collaborative task (Järvenoja et al., 2015; Schoor et al., 2015; Volet et al., 2009). Both types of social regulation can address different aspects of collaborative activity. In this sense, Saab, van Joolingen and van Hout-Wolters (2012) have identified two large groups of social regulatory processes that students can deploy: a) social regulation of the task, aimed at regulating the cognitive activities specifically involved in planning, running and supervising the learning task, and; b) social regulation of the group or team, associated with the management and coordination of collaboration among the students that make up said team. Formulating questions, providing explanations and clarifying procedures, are examples of actions related to task regulation. Meanwhile those interactions related to the organization and management of the group, such as agreeing the turns for participation and establishing agreements at the time of negotiation are examples of team regulation.

Some empirical studies about collaborative learning with multimedia have indicated that the level of learning reached by students depends to a large extent on the type and quality of the interactions that are put into play within the groups (Azevedo, Winters, \& Moos, 2004; Winters \& Alexander, 2011). For example, Winters and Alexander (2011) in a study about the regulatory processes in learning with hypermedia about the human circulatory system, observed that dyads are integrated by high school students achieved a greater gain in their learning when they were involved in high-level collaborative regulatory processes (e.g. establishing consensus, taking notes and summarizing information, assessing opinions and expressing feelings related to knowing), associated with joint understanding, generating high-quality inferences and engaging in a strategic processing of information.

To elicit social regulation processes aimed at both one and the other the task and the team, it is necessary to provide students with additional supports, especially when these students are lack of collaborative experience. In this regard, the joint construction of concept maps as an instructional strategy will perform the following functions, according to Cheng, Wang, \& Mercer (2014): a) shared targeting, since it would provide a common structure for organizing student contributions and guiding the discussions; b) cognitive reinforcement, by promoting the activation of 
elaboration mechanisms and joint negotiation of meanings; c) metacognitive support, that enables awareness of previous knowledge and the detection and compensation of the biases and gaps that may appear in the comprehension process; d) motivational and emotional aids, since it would help reduce anxiety and generate positive emotions related to internal learning goals; e) support for the execution and transfer, with the corresponding benefit for the improvement of the performance in the learning.

Furthermore, regarding multimedia learning, collaborative concept maps could cover two other specific functions: f) appropriate adjustment of the cognitive load, because, following Amadieu and Salmerón (2014), at least theoretically the collaborative concept mapping would generate a reduction of the cognitive load of others, allowing the learner to use the remaining cognitive resources in the specific processing of the elements of information presented in the materials and the interactivity required by the multimedia material (intrinsic cognitive load, which remains constant) direct the cognitive load relevant to the more sophisticated mental processes required by collaborative multimedia learning (Paas, Tuovinen, Tabbers, \& Van Gerven 2003); g) macro-structural reconstruction, enabling the connection of separate distant concepts, in addition to the activation of the inferential processes involved in the construction of a coherent global structure of non-linear information presented by multimedia (Amadieu, van Gog, Paas, Tricot, \& Mariné, 2009).

\subsection{Collaborative Learning with Concept Maps and Expository Summaries}

Like concept mapping, the elaboration of collaborative summaries can also represent a constructive and interactive task. In this sense, King (1992), following Wittrock, (1989), has highlighted the generative nature of this last task. For example, when a summary is made, students must go beyond the mere selection of the main ideas contained in a text, and it is required that they established connections between these ideas and their previous knowledge and experiences, simultaneously providing a structure for organizing a new text that reflects this integration (Kintsch, Caccamise, Franzke, Johnson, \& Dooley, 2007).

When the collaborative concept mapping has been compared respect to other tasks that present constructive characteristics and similar level of interactivity, the results that have been discrepant. For example, van Boxtel et al. (2000) found no differences in learning performance achieved by German high school students when they learned in dyads a content on physics (electricity) by collaboratively drawing concept maps and posters. However, there were significant differences in the quality of the interactions when the students did a previous phase of individual preparation, especially in the condition that worked with concept maps. In this condition, a greater number of discussions about concepts and a higher frequency of episodes of conflict negotiation were reported.

On the other hand, in their study on chemistry learning with collaborative concept maps, Fechner and Sumfleth (2008) compared a collaborative concept maps task with another task of collaborative elaboration of summaries. Prior to the development of these products, high school students carried out problem-solving activities involving small experiments related to everyday life. In the results, no differences were observed in the performance of both collaborative conditions, although there were variations in the way in which the contents were revised. However, another study conducted by Haugwitz et al. (2010) showed that students with cognitive abilities below the average reached a higher performance in a collaborative task of concept mapping, if they worked in groups where they interact with students who also had a low level of cognitive skills. This study involved high school students who learned in small groups (during several sessions) topics about the human circulatory system, through the development of collaborative concept maps and written expository summaries as strategies to synthesize what was learned in the sessions. In the collaborative products a greater number of valid propositions appeared in the condition that elaborated concept maps, but there were no differences in the learning of the groups where students with above-average cognitive abilities participated.

It is necessary, therefore, to have more empirical evidence about the effects of different types of collaborative tasks, including the collaborative construction of concept maps, performance in learning, the level of collaboration perceived in the groups and the social regulation that unfolds in these tasks. In this study the participants were grouped into 15 teams of three members. Each triad was assigned to one of the two conditions, namely: collaborative elaboration of a concept map and collaborative elaboration of an expository summary, based on the information presented in a hypermedia document on a subject of Psychology of Communication (Bateson's double bind theory). It was checked that there were no significant differences between the groups regarding reading comprehension, reading comprehension regulation strategies and domain-specific prior knowledge and in the elaboration of concept maps and summaries. The quality of the group concept maps was examined and the level of collaboration perceived by each member of the teams was assessed through a Likert scale. Likewise, the characteristics of the processes of social regulation that students put into play during collaborative work were identified qualitatively. Although the 
tasks considered in the study are initially constructive and interactive, both the metacognitive support (Hilbert and Renkl, 2008; Cheng et al., 2014) and the specific functions link to multimedia learning -adjustment of the cognitive load and reconstruction of the macro-structural coherence- (Amadieu et al., 2009; Amadieu \& Salmerón, 2014) would be more marked in the collaborative elaboration of concept maps. Therefore, students could have greater cognitive and metacognitive resources to direct them to the processes of social regulation, also causing a higher level of learning. Hence, the collaborative task with concept maps was expected to lead to a greatest performance in learning (Hypothesis 1). Likewise, it was hoped that this condition would promote higher collaboration levels in the teams that received it compared to the groups that worked in the elaboration of summaries (Hypothesis 2) and a more complex social regulation (Hypothesis 3).

\section{Methodology}

\subsection{Participants}

The participants were 45 Mexican university students of the subject the Psychology of Communication who attend first semesters of careers related to Social Sciences (17 women and 28 men). The mean age of the participants was 18.5 years. They were grouped into 15 triads, each of which was assigned to one of the following two collaborative conditions: a) groups that elaborate concept maps, b) groups that elaborate expository summaries. The participants were previously instructed in the elaboration of concept maps and expository summaries, in a previous 60-minute session (large group). The participation of the students was voluntary and as a bonus they received credits in the subject.

\subsection{Learning materials}

The learning material consisted of a digital multimedia document on interpersonal communication and Bateson's double bind theory (Bateson, 1985). The multimedia was structured in 5 blocks of content, which could be navigated in a non-linear way, namely: - systems theory, - axioms of communication, - contributions and Bateson's fields of work, bind and paradoxes theory and - conditions necessary for the double bind to arise. In the different blocks, written expository texts were combined with audio texts and podcasts. The multimedia document was developed with the Prezi program. Since the structure of the multimedia was non-linear, the participants had the ability to use it and explore it in the order they wanted.

\subsection{Instruments}

Except for the scores corresponding to the quality of the concept maps and the collaborative summaries, the rest of the measures were obtained from the individual application of the different instruments to the participants.

To assess students' reading comprehension skills, two tasks were used. On the one hand, the Gernsbacher and Varner's (1988) Multimedia Comprehension Battery (abbreviated version), adapted by Díez and Fernández (1997), it was applied to assess the levels of reading comprehension. In this test, the students were asked to read a computerized text "The most precious gift" and, after reading, answer eight items with a multiple-choice question format. Each successful question is counted with a point until it reaches a maximum of eight. On the other hand, a reading comprehension task of a short and simple expository text (111 words) was administered; after reading the text for 120 seconds, students are asked to point out the three main ideas of the three paragraphs the text consist of and the global idea of said text. The maximum score of this task is six.

For the assessment of strategies for reading regulation, the Assessment Inventory of Self-Regulated Learning from Texts - ARATEX - (Solano et al., 2005) was used. It consists of 23 items and the assessment is carried out through a Likert scale, with five response alternatives, in relation to the frequency with which they perform or not the activity described in the item ( $1=$ never; $5=$ always). For example, "When I finish the text, I check if I understand everything well".

The level of knowledge about the domain-specific, both pretest and post-test, was examined through a questionnaire with 10 questions on the subject of interpersonal communication using multiple-choice response. For example, one of the items was: "4. Point out the correct idea: According to Watzlawick (1967), communication can be ... a) only digital; b) only analog; c) analog and digital; d) none of the above." The maximum score that students can obtain in this questionnaire is 10 points.

To grade the level of collaboration perceived by the participants, the Collaboration Questionnaire devised by Chan and Chan (2011) was used, and developed based on the notion of collaborative knowledge construction proposed by Scardamalia and Bereiter (2006). This questionnaire comprises 12 items, valued according to a 5-point Likert scale. The different items reflect the 12 principles of collaborative learning proposed by Scardamalia and Bereiter (2006), 
according to the experience of collaboration that the students had in their respective teams. For example: "Our points of view and knowledge increased while working with others".

The quality of the products -that is, concept maps and expository summaries- that were obtained as a result of the collaborative activity was valued according to the number of correct relations between concepts that were made explicit in the propositions present in those products. Haugwitz et al. (2010) procedure was adapted, adjusting it to the specific knowledge area (interpersonal communication and Bateson's double bind theory). To this end, a list of 15 main proposals was drawn up that reflect the central ideas of the content presented in the multimedia material (for example, Proposition 4: "Meta-communication is the key of a strategy to get out of a double bind situation"). In cases in which the teams elaborated ideas not considered in said list, the pertinence and quality of the new proposal was assessed. One point was awarded for each correct proposition.

\subsection{Procedure}

The study was carried out in two sessions. In the first session (60 minutes), the students received instructions on the elaboration of concept maps and expository summaries and a modeling practice was carried out for the elaboration of both products, on a content of Psychology (Behavioral Psychology) different to the presented in the multimedia material of the experimental phase, using pencil and paper. Likewise, the instruments were applied to control the pre-test variables referring to reading comprehension and reading strategies regulation tests. In the second session (60 minutes), the domain-specific prior knowledge questionnaire was administered (10 minutes) and the instructions for completing the task were explained (5 minutes). Subsequently, the groups had 30 minutes for the collaborative learning task, reviewing the multimedia material and constructing the concept maps and the expository summaries according to the assigned condition. Finally, the participants answered both the domain-specific knowledge questionnaire and the self-assessment questionnaire on collaboration in teams. During the learning session, the students elaborated the concept maps and the expository summaries with digital pen (Smartpen Livescribe) that also gathered the verbal exchanges during the task. Subsequently, the concept maps were passed to CmapTools V. 5 [Computer Application] (IHMC, 2009) meanwhile the summaries and verbal exchanges on the computers were transcribed using a word processor.

\subsection{Coding Protocol}

The verbal exchanges of the participants were coded according to an analysis system that combines different qualitative proposals that describe the collaboration in a team (Castellanos-Ramírez \& Onrubia-Goñi, 2014; Järvelä, Malmberg \& Koivuniemi, 2016; Saab et al., 2012; Volet, Summers, \& Thurman, 2009). The students' production was segmented into episodes, that is, into a sequence of statements that are significant with respect to a given content (Van Boxtel et al., 2000). An episode consists of an interaction segment in which two or more students regulate a collaborative action. Each interactive sequence can be characterized according to the direction to which is addressed, namely: a) referred to the learning task, when it comes to conversations that allude, either the cognitive activity either to the cognitive activity (when they refer to aspects related to the product to elaborate or to the comprehension of the contents on which this product is concerned), or the metacognitive activity (when they refer to the establishment of goals, planning, progress monitoring in comprehension and in the development of the collaborative product, and the evaluation of the achievements in the task); or the metacognitive activity and, b) referred to the management of collaboration in the team, such as, the division of tasks, the organization of exchanges and agreements regarding participation turns. In addition, the type of social regulation established in each episode was identified according to the way in which the participation of students is distributed in the regulatory action, which may be: a) co-regulative, when a single apprentice exercises and dominates social regulation, while the rest of the team is limited to accompanying their regulatory proposals; or, b) shared, if multiple members of the team participate jointly in the regulatory processes, observing an interdependence in the operation of the team in that episode.

For the qualitative analysis the AtlasTi V6 program was used. For the quantitative data analysis, in which we have worked using a level of statistical significance of $\mathrm{p}<0.05$ and to analyze using the computer program Statistical Package for Social Science (SPSS) version V22.0 for Windows.

\section{Results}

A non-parametrical analysis was carried out to compare two independent samples, establishing the experimental condition (collaborative concept maps and collaborative expository summaries) as the group variable; and as dependent measurements, the different scores that assess both the quality of the propositions included in both collaborative products and the collaboration level perceived by students. Due to the impossibility to guarantee a normal 
distribution and the stability of the variance in variables, the non-parametric Mann-Whitney $U$ test was used, which is an excellent alternative to the parametric $t$ test.

No significant differences were found between the two conditions considered for this study (collaborative concept maps and collaborative expository summaries) in any of the measures of reading comprehension, learning regulation strategies nor in the level of domain-specific prior knowledge.

In the quantitative analysis of the results there were no significant differences in the quality of the collaborative products taking into account the presence and quality of the propositions included in both concept maps and expository summaries (Mann-Whitney $U=198.000 ; Z=-1.25 ; p=.28$ ). However, the analysis yielded evidence about the existence of significant differences between the two conditions regarding learning performance valued through the knowledge questionnaire, in favor of the condition of collaboratively working with concept maps. The students who worked collaboratively in the elaboration of a concept map obtained higher scores in the knowledge questionnaire (Mann-Whitney $U=111.000 ; Z=-3.27 ; p=.001$ ) than those students who developed the expository summary (See table 1).

Table 1. Means and standard deviations (in parentheses) of the scores in the variables referring to performance in learning.

\begin{tabular}{lll}
\hline Learning performance & $\begin{array}{l}\text { Condition 1 } \\
\text { (collaborative concept } \\
\text { maps) }\end{array}$ & $\begin{array}{l}\text { Condition 2 } \\
\text { (collaborative expository } \\
\text { summaries) }\end{array}$ \\
\hline Knowledge questionnaire & $5.50(1.69)$ & $4.00(1.22)$ \\
Total Propositions & $6.37(1.24)$ & $5.71(2.83)$ \\
$\begin{array}{l}\text { Inferential Propositions } \\
\text { Textual Propositions }\end{array}$ & $1.12(0.61)$ & $0.57(0.74)$ \\
\hline
\end{tabular}

Note. Max points for Knowledge questionnaire $=10$

Regarding the evaluation of collaborative products, only significant differences were found in the number of inferential propositions that were included in the concept maps elaborated by the teams who worked on that task (Mann-Whitney $\mathrm{U}=144.000 ; \mathrm{Z}=-2.669 ; \mathrm{p}=.008)$. No significant differences were observed in the number of textual propositions (Mann-Whitney $\mathrm{U}=252.000 ; \mathrm{Z}=.000 ; \mathrm{p}=1.000$ ), nor in the total of propositions (Mann-Whitney $\mathrm{U}=198.000 ; \mathrm{Z}=$ $-1.258 ; \mathrm{p}=.208$ ) that were presented in the collaborative products developed in the two compared conditions.

Significant differences were found in the total assessment of the levels of collaboration perceived by the students, in favor of the groups of the condition with collaborative concept maps. (Mann-Whitney $\mathrm{U}=137.500 ; \mathrm{Z}=-2.621 ; \mathrm{p}=.009$ ). Likewise, the items referred to Improvable Ideas were significantly higher (Mann-Whitney $U=150.000 ; Z=-2.535$; $\mathrm{p}=.011$ ), High level complex thinking (Mann-Whitney $\mathrm{U}=156.00 ; \mathrm{Z}=-2.351 ; \mathrm{p}=.019$ ), Diversity of ideas (Mann-Whitney U= 135.00; $Z=-2.843 ; \mathrm{p}=.004$ ), Democratization of knowledge (Mann-Whitney $U=167.500 ; \mathrm{Z}=$ -2.041; $\mathrm{p}=.041$ ) and Symmetric advances (Mann-Whitney $\mathrm{U}=265.00 ; \mathrm{Z}=-2.486 ; \mathrm{p}=.013$ ), in favor of the groups that carried out the task of elaborating collaborative concept maps (See table 2). 
Table 2. Means and standard deviations (in parentheses) of the scores corresponding to the level of perceived collaboration obtained by the groups of the two conditions

\begin{tabular}{|c|c|c|}
\hline & $\begin{array}{l}\text { Condition } 1 \\
\text { (collaborative concept } \\
\text { maps) }\end{array}$ & $\begin{array}{l}\text { Condition } 2 \\
\text { (collaborative } \\
\text { expository summaries) }\end{array}$ \\
\hline Improvable ideas & $4,25(.67)$ & $3.71 .64)$ \\
\hline $\begin{array}{l}\text { Community knowledge and collective } \\
\text { responsibility }\end{array}$ & $4.37(.71)$ & $4.23(.53)$ \\
\hline High-level complex thinking & $4.41(.71)$ & $3.90(.70)$ \\
\hline Diversity of ideas & $4.16(.81)$ & $3.47(.60)$ \\
\hline Democratizing knowledge & $4.12(.85)$ & $3.66(.73)$ \\
\hline Epistemic agency and negotiation of meanings & $3.62(.92)$ & $3.09(.70)$ \\
\hline $\begin{array}{l}\text { Discourse aimed at the construction of } \\
\text { knowledge }\end{array}$ & $4.16(.56)$ & $3.90(.30)$ \\
\hline Concurrent evaluation & $4.04(.75)$ & $3.85(.85)$ \\
\hline Symmetric advancement & $4.25(.60)$ & $3.85(.35)$ \\
\hline Constructive uses of information & $3.04(1.04)$ & $2.85(1.01)$ \\
\hline Authentic problems and real ideas & $4.25(.67)$ & $4.00(.70)$ \\
\hline Pervasive knowledge building & $4.08(.82)$ & $3.85(.91)$ \\
\hline Total & $4.06(.44)$ & $3.70(.18)$ \\
\hline
\end{tabular}

Note. Max points $=5$

Table 3 shows the results obtained in the qualitative analysis to identify and characterize the episodes of social regulation in the teams of both conditions. In the groups that elaborated collaborative concept maps, an average of 10.5 episodes of social regulation were recognized; while in the triads who collaborated in the elaboration of expository summaries the average was lower (about one episode less). In these last teams the co-regulatory episodes of the task directed towards their cognitive aspects predominated (little more than $45 \%$ of the episodes), while the metacognitive activity of the task was taken into account in $18 \%$ of the episodes, considering both types of social regulation (co-regulation and shared regulation). Furthermore, in the collaborative concept maps condition, the episodes of regulation aimed at metacognitive aspects of the task were presented in a slightly higher percentage (26\%, adding the two types of social regulation); and, the total percentage of episodes of shared regulation was also higher in comparison to the summaries condition (a sum of $50 \%$ of episodes, compared to less than $40 \%$ of the episodes in the teams that developed the summaries).

Despite these variations between the two conditions regarding social regulation displayed by the students in the groups, the chi-square test indicated that no significant differences were reached in any of the dimensions considered, namely: a) the social regulation of the task, in relation to both cognitive and metacognitive activity of co-regulatory type $(1, \mathrm{n}=45)=2.466, \mathrm{p}=0.116)$, of shared type $(1, \mathrm{n}=45)=0.056, \mathrm{p}=0.811)$, nor when comparing the total of episodes in both modalities of social regulation directed to the task $(1, \mathrm{n}=45)=1.864, \mathrm{p}=0.172)$; and, $\mathrm{b}$ ) social regulation aimed at collaborative management in each team, comparing the co-regulation and shared regulation frequencies $(1, \mathrm{n}=45)=0.016, \mathrm{p}=0.898)$. Likewise, there were no significant differences when comparing the totality of co-regulatory episodes and of shared regulation between the two conditions of the study $(1, n=45)=0.280$, $\mathrm{p}=0.596)$. 
Table 3. Frequencies and percentages of episodes of social regulation identified in the groups of the two conditions

\begin{tabular}{|c|c|c|c|c|c|}
\hline \multirow[t]{2}{*}{ Social regulation } & & \multirow{2}{*}{$\begin{array}{l}\text { Condition } 1 \\
\text { concept maps) } \\
n=8 \text { triads } \\
\mathrm{F}\end{array}$} & \multirow{2}{*}{$\begin{array}{l}\text { (collaborative } \\
\%\end{array}$} & \multicolumn{2}{|c|}{$\begin{array}{l}\text { Condition } 2 \text { (collaborative } \\
\text { expository summaries) } \\
n=7 \text { triads }\end{array}$} \\
\hline & & & & $\mathrm{f}$ & $\%$ \\
\hline \multicolumn{6}{|l|}{ Task regulation } \\
\hline \multirow[t]{2}{*}{ Co-regulative } & cognitive & 24 & 28.58 & 30 & 45.45 \\
\hline & metacognitive & 13 & 15.48 & 7 & 10.61 \\
\hline \multirow[t]{2}{*}{ Shared } & cognitive & 31 & 36.90 & 20 & 30.3 \\
\hline & metacognitive & 9 & 10.71 & 5 & 7.58 \\
\hline \multicolumn{6}{|l|}{ Team regulation } \\
\hline Co-regulative & & 5 & 5.95 & 3 & 4.55 \\
\hline Shared & & 2 & 2.38 & 1 & 1.51 \\
\hline Episodes total & & 84 & $100 \%$ & 66 & $100 \%$ \\
\hline Average & & 10.5 & & 9.42 & \\
\hline
\end{tabular}

\section{Discussion and Conclusion}

\subsection{Discussion of Results}

Collaborative learning requires apprentices to socially regulate the realization of a joint task, that is, to put into play a series of processes to plan, manage, monitor and evaluate interactions and exchanges during the group activity (Hadwin et al., 2011; Järvelä \& Hadwin, 2013). The type of task and the technological tools proposed in a collaborative learning situation can influence not only the performance achieved by the students and their perception of levels of collaboration reached during the activity, but also in the manner in which said processes of social regulation are deployed in the teams (Dillenbourg et al., 2009; Jeong \& Hmelo-Silver, 2016). Therefore, care must be taken to ensure that the tasks and tools employed are meaningful for the students and, also, adjusted to their characteristics, in order to generate productive interactions for learning (Kirschner, Paas, \& Kirschner, 2009). Even more so if you take into account that the use of technology can impose an additional cognitive load on learners that is not always generative (Paas et al., 2003).

In this work, two types of collaborative tasks were studied and compared: elaboration of concept maps and expository summary. These tasks, according to the ICAP framework (Chi, 2009; Chi \& Wyley, 2014), in principle have their own characteristics: on the one hand, of constructive activities, since they are emphasized on the activation of elaborative and inferential processes together with the metacognitive (revision and repair), essential for a deep understanding that makes possible the transfer of what has been learned; and, on the other hand, of the interactive activities, since being collaborative, they try to promote in the students processes of exchange, feedback and negotiation of meanings with respect to the contents presented, in order to jointly generate a new product, either a summary or a concept map. These tasks were framed in a context of learning based on the use of digital technologies (hypermedia). In this specific case, it was ensured that significant moments for learning were generated around the hypermedia tool and constructively interactive actions were fostered.

In this study, some of the proposed hypotheses could be partially verified. The results obtained in this study, showed a positive effect of the use of a collaborative concept maps in some of the aspects related to the learning level reached by the students, compared to the task of collaborative elaboration of the summaries. Significant differences were also found in favor of the condition that worked with concept maps in several of the twelve principles of collaboration considered in the questionnaire on perceived collaboration.

Regarding the performance in learning, compared to the summary elaboration task, the collaborative construction of a concept map allowed students to reach higher scores in the questionnaire to assess performance in learning. Likewise, 
the products that were elaborated in that condition included significantly greater number of inferential propositions. However, no significant differences were found in the total number of textual propositions presented in summaries and concept maps.

These results are largely consistent with previous studies that highlight the effectiveness of collaborative concept maps to increase learning with respect to other instructional strategies (Cañas et al., 2003; Stoyanova \& Kommers, 2002). The concept mapping would favor semantic processing in the visuospatial work memory, avoiding the overload of the verbal work memory, and, in addition, by using a simpler syntax than that required by the abstracts, they required simpler grammatical decisions that would liberate cognitive resources. to execute the processes of greater elaboration (Winn, 1991). Likewise, by collaboratively constructing concept maps, as pointed out by Liu, Chen, \& Chang (2010), students deploy and integrate a series of "bottom-up" processes, -such as, grasp the meaning of words and proportions, identify the main idea of the multimedia text, and to establish links with other propositions from it, organizing them in a hierarchical way to build a global idea -, as "top-down", related to the activation of the prior knowledge schemes and the establishment of new inferential links that go beyond what the text says. In this way, in the mapping task, the apprentices go over the relations between the concepts, while they remember and organize the information presented by the multimedia text integrating it with their prior knowledge. In this sense, following Cheng et al. (2014), the collaborative task with concept maps would have greater potentiality than a collaborative task with summaries that will function not only as a cognitive reinforcement but also as a support for the execution and transfer of learning. Especially if one takes into account that -as the greater frequency of inferential propositions that appear in these collaborative products seems to suggest- the task with concept maps would provide a high degree support to the elaboration function, propitiating the actions that allow the students to relate their prior knowledge with the new text information to determine the main ideas and their relations with other ideas (Hilbert, \& Renkl, 2008).

One of the key factors that Chi and Walley (2014) point out regarding to the effectiveness of a learning task is giving by how the students actually carry out the activity. Although the instructions giving to the students of both conditions were directed to underline the importance of using their own words to summarize and to elaborate the concept maps, it could be assumed, as a possible interpretation of the obtained results, that in several teams of the summaries condition the students limited themselves to follow a cut and paste strategy, assuming the task only in an active way and weakening, consequently, in its constructive character. In order to confirm this inference, it would be necessary to carry out an analysis of the exchanges with a much finer grain, taking into account not only the modality and orientation of the social regulation processes but also the complexity of the specific conceptual content that appears in the actions and strategies that they were followed during the development of the task

Furthermore, in reference to the performance in learning, the results that were obtained are in part consistent with the previous work of Haugwitz et al. (2010), despite the fact that significant differential effects have not been replicated in the total number of propositions that were included in the final collaborative products. In our study, considering the control variables (low levels of prior knowledge, reading comprehension and reading regulation skills), students with similar characteristics -that is, with a low level of cognitive abilities- to those who showed significant changes in the study by Hagwitz et al. (2010) participated. Regarding the discrepant results, a possible explanation could refer to the fact that very different learning environments were used and deal with specific contents of very different domains of knowledge. In the research by Haugwitz et al. (2010), which addressed the domain of knowledge of the natural sciences (human circulatory system), physical models of such content were presented as learning materials and cards with conceptual and relational information were provided in which, as support, the central concepts and their relations were highlighted. While in this study, non-linear multimedia material was used without any type of cognitive aid that could have generated possibly obstacles for the micro-structural processing of the content, as Amadieu and Salmerón (2014) refer to in regard multimedia learning with concept maps. In the research of Haugwitz et al. (2010) the cards will work as a support that would facilitate the identification of the main concepts and the construction of propositions, increasing the quality of the collaborative concept maps.

Regarding the level of perceived collaboration, the students who worked collaboratively on the concept maps significantly highlighted aspects related to the possibility of discussing a diversity of ideas when performing the task and improving them during their development. They also positively appreciated the fact that they were able to participate actively and provide contributions to develop the required product, establishing a symmetrical relationship between them and thinking together in a complex way. These results make clear the interactive potentialities of collaborative concept mapping as a learning task, since they allowed the students to exchange processes, feedback and meanings negotiation regarding the content, in order to jointly generate a new product, such as indicated by Chi and Wylie (2014). 
In this sense, these results follow the evidence provided by several previous studies (Janssen et al., 2010; Roth \& Roychoudhur, 1993; van Boxtel et al., 2002) that foreground the potentialities of a learning task with concept maps to favor to the explicitation of students' ideas and to foster their involvement in negotiation and consensus actions in the construction of new meanings from the information presented in a learning material. According to Cheng et al. (2014), concept maps would underpin the shared focus function, as they will provide a common structure to organize student contributions and team discussions.

In reference to the type of regulatory processes that students put into play when they interacted in the teams, the differences between the tasks did not become statistically significant. In both conditions, episodes of social regulation directed to the cognitive aspects of the collaborative task prevailed. However, in the collaborative task with concept maps the students showed greater metacognitive regulation and, in addition, a higher percentage of episodes of shared regulation could be registered, even though the contrast between the conditions did not reach a statistical significance. In this regard, it should be borne in mind, on the one hand, that the small sample size in this study was not sufficient to observe any significant difference with respect to the regulatory processes between the collaborative conditions. But also, on the other hand, it should be noted that in both conditions the percentage of regulatory episodes was quite low, especially those related to the regulation of the team. Data that has also been highlighted by recent research that reports the difficulties of students to put this kind of regulation into play spontaneously (Rogat \& Linnenbrink-Garcia, 2011, Summers \& Volet 2010).

Therefore, it would be convenient to develop specific support to favor the deployment of these processes linked to group work collaboration structures management. Recent researches have emphasized the importance of providing different kinds of supports that favor the implementation of social regulatory processes in collaborative learning (Hadwin et al., 2011, Järvelä and Hadwin, 2013, Järvenoja et al., 2105). For example, aid has been developed through different types of prompts, feedbacks or scaffoldings, either directed to motivational processes (Schoor, Kownatzki, Narciss, \& Körndle, 2014) or to metacognitive processes (Molenaar et al., 2014; Molenaar, Roda, van Boxtel, \& Sleegers, 2012) involved in collaborative regulation. Another way to support the regulation of collaborative learning is to provide students with a series of external scripts that allow them to structure their collaborative actions, for example, inducing certain activities, prescribing certain sequences for the realization of each activity and also distributing the specific roles that students must play when they are involved in the collaborative task (Fischer, Kollar, Stegmann, Wecker, \& Zottmann, 2013). Likewise, the instruction and training of communication skills in students could contribute to improve the regulatory processes in the collaborative task. An example of this type of support is the RIDE instructional scaffolding, proposed by Saab and collaborators (Saab et al., 2007, 2012), which consists of the instruction of a series of collaboration norms that arise from different works about effective collaboration (King, 1997; Mercer, 1996). In this support, prior to the collaborative task, students are instructed in a series of standards for collaboration, grouped under the following four principles: a) Respect, which highlights the importance that all members of a team always have the opportunity to speak and that each of the ideas put forward be considered in depth; b) Intelligent collaboration, which highlights actions related to sharing all the relevant information and proposing suggestions of interest, clarifying the information given, explaining the answers given and making and accepting criticisms in an appropriate manner; c) Deciding together, which emphasizes the need to make agreements explicit -prior to making decisions and carrying out an action- and to consider that the group is responsible for decisions and actions (and not a specific member); and, d) Encouragement, which refers to the value of promoting communicative actions, such as asking for explanations, asking if something is not understood and giving positive feedback.

\subsection{Results Limitations and Future Directions}

This study has two main limitations: first, the sample size was not very broad, so it probably was not enough to find significant differences, from a statistic point of view, regarding the social regulation that students deployed in their teams. A second limitation refers to the fact that a single domain of knowledge was examined, related to the human sciences (interpersonal communication). It has been pointed out that the domain of knowledge could influence the effect of tasks (Haugwitz et al., 2010; Nesbit \& Adesope, 2006).

Therefore, in future studies, it would be advisable to replicate the study with other domains of knowledge, such as, subjects corresponding to the natural sciences, especially if one takes into account that a large part of the research work on collaborative concept maps covers topics of said domain. In addition, it would be advisable to perform finer grain analysis on the contents of student exchanges in the teams since they could provide evidence about the relation between the quality and relevance of said contents and the results obtained in regard to performance in learning.

Nevertheless, in subsequent studies it might be convenient to examine the self-regulation levels of the participants since the self-regulated learning skills could also have an impact on the development of collaborative learning tasks 
(Hadwin et al., 2011; Järvelä \& Hadwin, 2013). For example, Järvelä et al. (2016) has found some connections between the self-regulated learning skills of individual students and the results of collaborative learning.

\subsection{Overall Conclusion}

In this study, favorable evidence was found for the collaborative task with concept maps in variables referring to the performance in learning and in the levels of collaboration indicated by the students, in comparison with a collaborative task of writing summaries. While in its initial design both tasks are intended to assume constructive and interactive features, according to the ICAP structure (Chi, 2009, Chi and Waley, 2014), the task of collaborative development of concept maps from information presented in multimedia material would enable a greater cognitive implication of the students and would provide a common structure to organize their contributions and to guide the discussions in the teams. It would allow, therefore, a higher level of constructive actions and restrict the possibility for students to limit themselves to follow merely active strategies, with little inferential activity.

\section{Acknowledgments}

This work integrates a series of studies in progress on collaboration and digital technologies that were carried out within the framework of the research project called "Communicative innovation and management in organizations" of the Thematic Network of Academic Collaboration "Management, Culture and Communication in Organizations", which was supported by PRODEP-SEP (México) DSA/103.5/15/11048 (UASLP-CA-232), in which the first author participated. In addition, the authors thank Juan Pedro Navarro Agraz for translating this article into English and a María Eugenia Ávila Mayor for reviewing the translation.

\section{References}

Acuña, S., López-Aymes, G., \& Gabino-Campos, M. A. (2012). Co-regulación y función comunicativa de los intercambios en el aprendizaje colaborativo con mapas conceptuales. In A. J. Cañas, J. D. Novak, J. Vanhear (Eds.), Concept Maps: Theory, Methodology, Technology, 1, 65-72. Valletta, Malta: University of Malta and HIMC.

Amadieu, F., \& Salmerón, L. (2014). Concept maps for comprehension and navigation of hypertexts. In R. Hanewald, \& D. Ifenthaler (Eds.), Digital Knowledge Maps in Education, 41-59. Nueva York: Springer.

Amadieu, F., van Gog, T., Paas, F., Tricot, A., \& Mariné, C. (2009). Effects of prior knowledge and concept-map structure on disorientation, cognitive load, and learning. Learning and Instruction, 19(5), 376-386. http://dx.doi.org/10.1016/j.learninstruc.2009.02.005.

Azevedo, R., Winters, F. I., \& Moos, D. C. (2004). Can students collaboratively use hypermedia to learn science? The dynamics of self- and other-regulatory processes in an ecology classroom. Journal of Educational Computing Research, 31(3), 215-245. https://doi.org/10.2190/HFT6-8EB1-TN99-MJVQ.

Basque, J., \& Lavoie, M.-C. (2006). Collaborative concept mapping in education: major research trends. In A. J. Cañas, J. D. Novak (Eds.), Concept Maps: Theory, Methodology, Technology. Proceeding of the Second International Conference on Concept Mapping (Vol. 1) (pp. 79-86). San José, Costa Rica: Universidad de Costa Rica.

Bateson, G. (1985). Pasos hacia una ecología de la mente. Buenos Aires: Carlos Lohlé.

Cañas, A. J., Coffey, J. W., Carnot, M. J., Feltovich, P., Hoffman, R. R., Feltovich, J., \& Novak, J. D. (2003). A summary of literature pertaining to the use of concept mapping techniques and technologies for education and performance support (Report to The Chief of Naval Education and Training). Pensacola, FL: Institute for Human and Machine Cognition.

Castellanos-Ramírez, J. C., \& Onrubia-Goñi, J. (2016). Regulación compartida en entornos de aprendizaje colaborativo mediado por ordenador: diferencias en grupos de alto y bajo rendimiento. RIED: Revista Iberoamericana de Educación a Distancia, 19(1), 233-251. https://doi.org/10.5944/ried.19.1.14036.

Chan, C., \& Chan, Y. (2011). Students' views of collaboration and online participation in Knowledge Forum. Computers and Education, 57, 1445-1457. https://doi.org/10.1016/j.compedu.2010.09.003.

Chang, K. E., Sung, Y. T., \& Chen, S. F. (2001). Learning through computer - based concept mapping with scaffolding aid. Journal of Computer Assisted Learning, 17(1), 21-33. https://doi.org/10.1111/j.1365-2729.2001.00156.x.

Cheng, B., Wang, M., \& Mercer, N. (2014). Effects of role assignment in concept mapping mediated small group learning. The Internet and Higher Education, 23, 27-38. https://doi.org/10.1016/j.iheduc.2014.06.001 
Chi, M. T. H. (2009). Active - constructive - interactive: A conceptual framework for differentiating learning activities. Topics in Cognitive Science, 1(1), 73-105. https://doi.org/10.1111/j.1756-8765.2008.01005.x

Chi, M. T. H., \& Menekse, M. (2015). Dialogue patterns in peer collaboration that promote learning. In L. B. Resnick, C. S. C. Asterhan, \& S. N. Clarke (Eds.), Socializing intelligence through academic talk and dialogue, 263-274. Washington, D.C.: AERA.

Chi, M. T. H., \& Wylie, R. (2014). The ICAP framework: Linking cognitive engagement to active learning outcomes. Educational Psychologist, 49(4), 219-243. https://doi.org/10.1080/00461520.2014.965823

Díez, E., \& Fernández, A. (1997). Batería multimedia de comprensión (versión abreviada). Salamanca, España: Universidad de Salamanca.

Dillenbourg, P., Järvelä, S., \& Fischer, F. (2009). The evolution of research on computer supported collaborative learning: From design to orchestration. In N. Balacheff, S. Ludvigsen, T. de Jong, T. A. Lazonder, \& S. Barnes (Eds.), Technology-enhanced learning. Principles and products, 3-19. Doetinchem, Netherlands: Springer.

Fechner, S., \& Sumfleth, E. (2008). Collaborative concept mapping in context-oriented chemistry learning. In A. J. Cañas, P. Reiska, M. Åhlberg, \& J. D. Novak (Eds.), Concept mapping: Connecting educators. Proceedings of the Third International Conference on Concept Mapping, 152-156. Põltsamaa, Estonia: OÜ Vali Press.

Fischer, F., Kollar, I., Stegmann, K., Wecker, C., \& Zottmann, J. (2013). Collaboration scripts in computer-supported collaborative learning. In C. E. Hmelo-Silver, A. M. O’Donnell, C. A. Chinn; \& C. Chan C. (Eds.), The International Handbook of Collaborative Learning, 403-419. New York: Routledge.

Gao, H., Shen, E., Losh, S., \& Turner, J. (2007). A review of studies on collaborative concept mapping: What have we learned about the technique and what is next? Journal of Interactive Learning Research, 18(4), 479-492.

Gernsbacher, M. A., \& Varner, K. R. (1988). The multimedia comprehension battery. Eugene, OR: University of Oregon, Institute of Cognitive and Decision Sciences.

Hadwin, A. F., Järvelä, S., \& Miller, M. (2011). Self-regulated, co-regulated, and socially shared regulation of learning. In B. J. Zimmerman \& D. H. Schunk (Eds.), Handbook of self-regulation of learning and performance, 65-84. New York: Routledge.

Haugwitz, M., Nesbit, J. C., \& Sandmann, A. (2010). Cognitive ability and the instructional efficacy of collaborative concept mapping. Learning and individual differences, 20(5), 536-543. https://doi.org/10.1016/j.lindif.2010.04.004

Hilbert, T. S., \& Renkl, A. (2008). Concept mapping as a follow-up strategy to learning from texts: what characterizes good and poor mappers? Instructional Science, 36(1), 53-73. http://dx.doi.org/ 10.1007/s11251-007-9022-9

Hilbert, T. S., \& Renkl, A. (2009). Learning how to use a computer-based concept-mapping tool: Self-explaining examples helps. Computers in Human Behavior, 25, 267-274. http://dx.doi.org/10.1016/j.chb.2008.12.006

IHMC (2009). CmapTools V. 5 [Aplicación Informática]. Institute for Human and Machine Cognition. http://cmap.ihmc.us.

Janssen, J., Erkens, G., Kirschner, P. A., \& Kanselaar, G. (2010). Effects of representational guidance during computer-supported collaborative learning. Instructional Science, 38, 59-88. https://doi.org/10.1007/s11251-008-9078-1

Järvelä, S., \& Hadwin, A. F. (2013). New frontiers: Regulating learning in CSCL. Educational Psychologist, 48(1), 25-39. https://doi.org/10.1080/00461520.2012.748006

Järvelä, S., Malmberg, J. \& Koivuniemi, M. (2016). Recognizing socially shared regulation by using the temporal sequences of online chat and $\operatorname{logs}$ in CSCL. Learning and Instruction, 42, 1-11. https://doi.org/10.1016/j.learninstruc.2015.10.006

Järvenoja, H., Järvelä, S., \& Malmberg, J. (2015). Understanding Regulated Learning in Situative and Contextual Frameworks. Educational Psychologist, 50(3), 204-219. http://dx.doi.org/10.1080/00461520.2015.1075400

Jeong, H., \& Hmelo-Silver, C. E. (2016). Seven Affordances of Computer-Supported Collaborative Learning: How to Support Collaborative Learning? How Can Technologies Help? Educational Psychologist, 51(2), $247-265$. https://doi.org/10.1080/00461520.2016.1158654 
Jonassen, D. H., Lee, C. B., Young, C. C., \& Laffey, J. (2005). The Collaboration principle in Multimedia Learning. In R. Mayer (Ed.), Cambridge Handbook of multimedia learning, 247-270. Cambridge: Cambridge University Press.

King, A. (1992). Comparison of Self-Questioning, Summarizing, and Notetaking-Review as Strategies for Learning From Lectures. American Educational Research Journal, 29(2), 303-323.

King, A. (1997). ASK to THINK-TEL WHY: A model of transactive peer tutoring for scaffolding higher level complex learning. Educational Psychologist, 32(4), 221-235. https://doi.org/10.1207/s15326985ep3204_3

Kintsch, E., Caccamise, D., Franzke, M., Johnson, N., \& Dooley, S. (2007). Summary street: Computer-guided summary writing. In T. K. Landauer, D. S. McNamara, S. Dennis, \& W. Kintsch (Eds.), Handbook of latent semantic analysis, 263-277. Mahwah, NJ: Erlbaum.

Kirschner, F., Paas, F., \& Kirschner, P. A. (2009). A cognitive load approach to collaborative learning: United brains for complex tasks. Educational Psychology Review, 21(1), 31-42. doi:10.1007/s10648-008-9095-2

Lehtinen, E., Hakkarainen, K., Lipponen, L., Rahikainen, M., \& Muukkonen, H. (1999). Computer-supported collaborative learning: A review of research and development. The J.H.G.I Giesbers Reports on Education, 10. Netherlands: University of Nijmegen, Department of Educational Sciences. Retrieved from http://www.kas.utu.?/clnet/clnetreport.html.

Liu, P. L., Chen, C. J., \& Chang, Y. J. (2010). Effects of a computer-assisted concept mapping learning strategy on EFL college students' English reading comprehension. Computers \& Education, 54(2), 436-445. http://dx.doi.org/10.1016/j.compedu.2011.03.015

Manlove, S., Lazonder, A. W., \& de Jong, T. (2009). Collaborative versus individual use of regulative software scaffolds during scientific inquiry learning. Interactive Learning Environments, 17(2), 105-117. http://dx.doi.org/10.1080/10494820701706437

Mercer N. (1996) The quality of talk in children's collaborative activity in the classroom. Learning and Instruction, 6 , 359-375. http://dx.doi.org/10.1016/S0959-4752(96)00021-7

Molenaar, I., Sleegers, P., \& van Boxtel, C. (2014). Metacognitive scaffolding during collaborative learning: a promising combination. Metacognition and learning, 9(3), 309-332. doi:10.1007/s11409-014-9118-y

Molenaar, I., Roda, C., van Boxtel, C., \& Sleegers, P. (2012). Dynamic scaffolding of socially regulated learning in a computer-based learning environment. Computers \& Education, 59(2), 515-523. https://doi.org/10.1016/j.compedu.2011.12.006

Nesbit, J. C., \& Adesope, A. O. (2006). Learning with concept and knowledge maps: A meta-analysis. Review of Educational Research, 76, 413-448. https://doi.org/10.3102/00346543076003413

O’Donnell, A. M., \& Hmelo-Silver, C. E. (2013). Introduction: What is collaborative learning? An overview. In C. E. Hmelo-Silver, C. A. Chinn, C. Chan, \& A. M. O'Donnell (Eds.), The international handbook of collaborative learning, 1-15. New York: Routledge.

Paas, F., Tuovinen, J., Tabbers, H., \& Van Gerven, P. (2003). Cognitive load measurement as a means to advance cognitive load theory. Educational Psychologist, 38, 63-71. https://doi.org/10.1207/S15326985EP3801_8

Rogat, T. K., \& Linnenbrink-Garcia, L. (2011). Socially shared regulation in collaborative groups: An analysis of the interplay between quality of social regulation and group processes. Cognition and Instruction, 29(4), 375-415. https://doi.org/10.1080/07370008.2011.607930

Roth, W. M., \& Roychoudhury, A. (1993). The concept map as a tool for the collaborative construction of knowledge: A microanalysis of high school physics students. Journal of research in science teaching, 30(5), 503-534. https://doi.org/10.1002/tea.3660300508

Saab, N., van Joolingen, W. R., \& van Hout-Wolters, B. (2007). Supporting communication in a collaborative discovery learning environment: The effect of instruction. Instructional Science, 35, 73-98. http://dx.doi.org/10.1007/s11251-006-9003-4

Saab, N., van Joolingen, W. R., \& van Hout-Wolters, B. (2012). Support of the collaborative inquiry learning process: influence of support on task and team regulation. Metacognition and Learning, 7, 7-23. http://dx.doi.org/10.1007/s11409-011-9068-6 
Scardamalia, M., \& Bereiter, C. (2006). Knowledge building: theory, pedagogy, and technology. In R. K. Sawyer (Ed.), The Cambridge Handbook of The Learning Sciences, 97-119. New York: Cambridge University Press.

Schoor, C., \& Bannert, M. (2012). Exploring regulatory processes during a computer-supported collaborative learning task using process mining. Computers in Human Behavior, 28(4), 1321-1331. https://doi.org/10.1016/j.chb.2012.02.016

Schoor, C., Kownatzki, S., Narciss, S., \& Körndle, H. (2014). Efectos de la retroalimentación de la motivación en un grupo de aprendizaje colaborativo. Electronic Journal of Research in Educational Psychology, 12(1), 191-210. http://dx.doi.org/10.14204/ejrep.32.13077

Schoor, C., Narciss, S., \& Körndle, H. (2015). Regulation During Cooperative and Collaborative Learning: A Theory-Based Review of Terms and Concepts. Educational Psychologist, 50(2), 97-119. http://doi.org/10.1080/00461520.2015.1038540

Solano, P., Núñez, J. C., González-Pienda, J. A., Álvarez, L., González, P., González-Pumariega, S., Roces, C., \& Rodríguez, S. (2005). Análisis de la fiabilidad, validez de la escala ARATEX. Actas do VIII Congresso Galaico-Portuguès de Psicopedagogía (pp. 647-658). Braga: Universidade do Minho.

Stoyanova, N., \& Kommers, P. (2002). Concept mapping as medium of shared cognition in computer-supported collaborative problem solving. Journal of Interactive Learning Research, 13(1-2), 111-133.

Summers, M., \& Volet, S. (2010). Group work does not necessarily equal collaborative learning: evidence from observations and self-reports. European Journal of Psychology Educational, 25, 473-492. https://doi.org/10.1007/s10212-010-0026-5

van Boxtel, C., van der Linden, J. L., \& Kanselaar, G. (2000). Collaborative learning tasks and the elaboration of conceptual knowledge. Learning and Instruction, 10, 311-330. http://dx.doi.org/10.1016/S0959-4752(00)00002-5

van Boxtel, C., van der Linden, J., Roelofs, E. \& Erkens, G. (2002). Collaborative concept mapping: Provoking and supporting meaningful discourse. Theory into Practice, 41(1), 40-46. http://dx.doi.org/10.1207/s15430421tip4101_7

Volet, S., Vauras, M., \& Salonen, P. (2009). Self- and social regulation in learning contexts: An integrative perspective. Educational Psychologist, 44(4), 215-226. https://doi.org/10.1080/00461520903213584

Volet, S., Summers, M., \& Thurman, J. (2009). High-level co-regulation in collaborative learning: How does it emerge and how is it sustained? Learning and Instruction, 19(2), 128-143. http://dx.doi.org/10.1016/j.learninstruc.2008.03.001

Winn, W. (1991). Learning from maps and diagrams. Educational Psychology Review, 3(3), 211-247. https://doi.org/10.1007/BF01320077

Winters, F. I., \& Alexander, P. A. (2011). Peer collaboration: the relation of regulatory behaviors to learning with hypermedia. Instructional Science, 39, 407-427. https://doi.org/10.1007/s11251-010-9134-5

Wittrock, M.C. (1989). Generative processes of comprehension. Educational Psychologist, 24, 345-376. https://doi.org/10.1207/s15326985ep2404_2 